\title{
Incidence of stroke in the diabetic and non-diabetic population in Upper Austria (2008-2012) and related effect measures
}

\author{
Karl Schableger \\ Lisa Inreiter \\ Oberösterreichische Gebietskrankenkasse Oberösterreichische Gebietskrankenkasse
}

\begin{abstract}
Background and Purpose: Although it is generally known that diabetes has a negative effect on the stroke incidence, only a limited number of long-term population-based studies focus on the comparison of incidence rates of stroke in diabetics and non-diabetics. Hence, the aim of this study was to estimate the risk of stroke in the diabetic and the non-diabetic population. Methods: For this study, data from the Upper Austrian stroke register and the statutory Upper Austrian health insurance (1.3 million members) was used to analyse all first strokes from 2008-2012. This was done by assessing stroke incidence for the total, the diabetic and the nondiabetic population. The analysis was mainly conducted on an age/sex-specific basis. Moreover, age/sex-standardized incidence rates were calculated as well. In addition, effect measures like the relative risk, the attributable risk among exposed and the population attributable risk were computed. Results: Out of the total cohort of 1,319,761 subjects, 17,663 had a first stroke (mean age (Sd.): 71.6 (14.3) years; 46.0 per cent male). Among these, 19.5 per cent were classified as diabetics. Concerning the stroke standardized incidence rates of the Upper Austrian population (per 100,000 person years), the following results were obtained for the diabetic and the non-diabetic population respectively: men: 571.9 (95\%-confidence interval: 530.1-613.6), 319.3 (95\%-confidence interval: 311.3-327.2); women: 600.9 (95\%-confidence interval: 559.3-642.5), 343.5 (95\%-confidence interval: $335.7-351.3)$. The age-standardized relative risk was found to be 1.79 (95\%-confidence interval: 1.66-1.93) for men and 1.75 (95\%-confidence interval: 1.63 1.88 ) for women. Attributable risks among exposed are as follows: men: 0.44 (95\%-confidence interval: $0.40-0.48$ ); women: 0.43 (95\%-confidence interval: $0.39-0.47$ ). For the population attributable risks 0.08 (95\%-confidence interval: 0.04-0.11) was obtained for men and 0.07 (95\%confidence interval: 0.04-0.09) for women. Conclusion: This investigation showed that the stroke risk in the diabetic population is significantly higher compared to the non-diabetic population.
\end{abstract}

Keywords: stroke, diabetes, epidemiology, Health Service Research, effect measures.

\section{Introduction}

Over the past few years a number of studies have confirmed that diabetes is a risk factor for stroke events (Almdal et al. 2004; Grysiewiez et al. 2008; Icks et al. 2011). The Austrian Stroke Society published a position paper on the prevention of stroke among diabetics and on the treatment of diabetic stroke patients which stresses the importance of this issue (Österreichische Schlaganfallgesellschaft, 
Positionspapier 2010). In 1989 the World Health Organization (WHO) and the International Diabetes Federation (IDF) announced the reduction of the incidence of stroke in diabetes as one of the prior objectives of the St. Vincent declaration in Europe. Their major goal was to bring the incidence of stroke in diabetics to the same level as in the non-diabetic population. Therefore, the knowledge of incidence rates is important and has been dealt with by many studies. However, it must be pointed out that a considerable number of these studies analyse only small cohorts, are meta-analyses or reviews (Lackland et al. 2014, Truelsen et al. 2006). In fact, the number of long term population based European studies are only limited. Icks et al. (2011) even argued that, studies conducted over a period of several years on a large population, investigating stroke incidence among diabetics and nondiabetics are lacking. Icks et al. (2011) for instance conducted such a large population based study for Germany.

For this reason, population based epidemiologic studies dealing with multiple years are important in order to determine incidence rates. Furthermore, studies that treat original data on a large proportion of a population do also generate a useful base of comparison for reviews, cohort and clinical studies.

Thus, the aim of this study was to estimate the risk of stroke for diabetics and non-diabetics using data of a stroke register and insurance data covering almost the complete Upper Austrian population over a period of five years. This was done by determining (age/sex-standardized) incidence rates, relative and attributable risks. Moreover, in order to offer a base of comparison to other studies, the results were not only standardized to the Upper Austrian but also to the Austrian and European population. ${ }^{1}$

Section 2 gives brief information about diabetes and stroke for readers with minor medical background. Data, material and used effect measures are described in Section 3. Results are presented in Section 4, while study findings, conclusions, study limitations and strength are discussed in Section 5.

\section{Medical descriptions}

\subsection{Diabetes mellitus}

Diabetes mellitus or simply diabetes is characterized by chronic hyperglycaemia (high blood sugar), which results from defects in insulin secretion and/or defects in insulin action. Suffering from diabetes mellitus may result in lasting damage, dysfunction or failure of various organs like heart, kidneys, eyes and blood vessels. The majority of cases of diabetes can be classified into two major categories that are referred to as type 1 and type 2 diabetes.

The main cause for type 1 diabetes is $\beta$-cell destruction. Due to the body's failure to produce insulin, most of the cases require insulin injections in order to be able to survive.

Type 2 diabetes is the most common form of diabetes. Patients with type 2 diabetes suffer from insulin resistance due to the fact that their cells fail to use insulin properly. Moreover, they usually display relative rather than absolute insulin deficiency. As the duration of this complaint advances, $\beta$-cell failure increases as well. However, people suffering from this kind of diabetes normally do not need insulin treatment. The risk of getting this kind of diabetes increases with obesity, physical inactivity and age. Moreover, individuals whose parents or siblings are suffering from the disease as well as people with hypertension or dyslipidaemia have an increased risk of developing type 2 diabetes. (Kahn and Sempson 1989; p. 45)

\subsection{Stroke}

A stroke or "brain attack" is defined as an interruption of blood flow to an area of the brain caused by either a blood clot blocking an artery or a breaking blood vessel. Due to this reason, brain cells begin to die and as a result brain damage occurs. Strokes can be classified into two main categories: ischaemic and haemorrhagic strokes. (National Stroke Association 2013)

\footnotetext{
${ }^{1}$ The interpretation of the standardized incidence rates for Austria and Europe has to be done carefully, due to the projection of regional data to other populations.
} 
If the blood flow of an artery supplying the brain is interrupted due to the disturbance of blood vessels caused for instance by blood clots, then this may cause cerebral thrombosis or cerebral embolism. This is often followed by a cerebral infarction or a transient cerebral ischaemic attack. These are globally subsumed under ischaemic strokes. (Ross 2012; p. 13)

The result of a breaking blood vessel inside or around the brain is known as bleeding or haemorrhage. While subarachnoid haemorrhage affects arteries at the surface of the brain, intracerebral and intracranial haemorrhages affect vessels within the brain and the skull respectively. (Ross 2012; p. 13)

\section{Materials and methods}

\subsection{Definition of the study population and statistical analysis}

For this study data from the Upper Austrian stroke register (UASR) was used. This register is operated by the statutory Upper Austrian health insurance company called "Oberösterreichische Gebietskrankenkasse" (OÖGKK) in cooperation with the regional government of Upper Austria ("Landesregierung Oberösterreich") and is known as "Oberösterreichische Integrierte Versorgung Schlaganfall" (OÖIVS). Besides the 14 Upper Austrian hospitals, there are a number of other institutions that are reporting data to the UASR. These include a pension insurance company, three rehabilitation centres and an ambulance company.

As a regional health insurance company, the OÖGKK insures about 86 per cent of the Upper Austrian residents. The only population groups that are not covered are farmers, teachers, officials and employers.

From 2008 to 2012 1,386,000 people were protected by the OÖGKK. However, not every single individual lived through this whole period of 5 years, as there are some who were born (about 80,000) during these years and others who died (about 55,000). By looking at the standardized person years from 2008 to 2012, it is visible that about 1.3 million people were secured, which roughly represents the amount of individuals protected by the OÖGKK.

For all members of this insurance company not only demographic data exists, but also pharmaceutical prescriptions and hospitalizations are available. Furthermore, data from all subjects who were members of the OÖGKK and for which the OÖGKK bears the costs are included.

Starting in 2007, the UASR includes 97.6 per cent of all hospitalized strokes in Upper Austria $(\mathrm{n}=$ 35,195). Following the WHO definition, strokes were defined with the help of "International Classification of Diseases-10" (ICD-10) codes of hospital admissions (BMG, 2012). These included subarachnoid haemorrhage (I60), intracerebral haemorrhage (I61), intracranial haemorrhage (I62) and cerebral infarction (I63). Apart from transient global amnesia (G45.4), transient cerebral ischaemic attacks and related syndromes (G45) were included as well. Moreover, strokes that were not specified as haemorrhage or infarction (I64) were also considered.

To carry out this investigation, the register was accumulated with data from the statutory Upper Austrian health insurance company. In order to identify diabetics and to determine the number of person years, 275,600,810 individual performance information of the reference year 2007 and the observation period 2008 to 2012 were used. Therefore, some of the challenges were due to the big data set.

Like Icks et al., only individuals who did not have a brain attack in 2007 (a period free from stroke of at least one year) were taken into account. Among these people only first strokes between 2008 and 2012 were counted. Due to this, the inclusion of recurrent strokes was avoided. (Icks et al. 2011)

Diabetic subjects were identified by a procedure established by Köster et al.. This procedure leads to a diagnosis of diabetes given that the individuals showed at least one of the following three characteristics: (a) diabetes diagnoses (ICD E10-E14) in at least three of four consecutive quarters, (b) at least two prescriptions of anti-diabetic medication within twelve months, (c) at least one prescription of an anti-diabetic medication and one diabetes diagnosis or one measurement of blood glucose or glycated hemoglobin (HbA1c) within twelve months. (Köster et al. 2006) 
However, Köster et al.'s algorithm, which only considers a single year, was slightly redefined. As this study evaluates diabetic subjects over a period of five years, the subjects were not monitored at an annual monthly rate but continuously over the whole period of interest. By doing this, diabetics could be defined more accurately.

Initially diabetics were determined during 2007. However, it must not be forgotten that a considerable number of people showed diabetic symptoms for the first time during the period of investigation. Table 1 shows for instance that almost 20,000 people changed from non-diabetics to diabetics during the five years of observation.

Instead of assigning the individuals for the whole period to diabetics and non-diabetics based only on their status in 2007, the months of each individual equal to the time they lived as diabetics or nondiabetics were counted. Therefore, all those who were diagnosed as diabetics between 2008 and 2012 were also taken into account. Due to the calculation of the person years (months) during this period, they could be weighted according to the duration of their disease. The number of person years where these individuals did not show diabetic symptoms was deleted in order to make sure that they did not have a stroke for at least one year.

Table 1: Number of people (per year) showing diabetic symptoms for the first time

\begin{tabular}{|l|l|}
\hline Year & $\mathrm{n}$ \\
\hline 2007 & 41,315 \\
2008 & 4,628 \\
2009 & 4,504 \\
2010 & 4,346 \\
2011 & 4,029 \\
$2012^{*}$ & 1,511 \\
\hline Overall & 60,330 \\
\hline
\end{tabular}

* Due to the determination of diabetics similar to a smoothing average the number of diabetics is lower at the end of the observation period. Esteve et al. (1994) mentioned that it is essential to

calculate the number of person years of an observation in an exact way. Therefore, the final date of the follow-up must be taken into account for each individual (Esteve et al. 1994; p.15). Moreover, following the procedure of Icks et al.'s study of 2011, the cohort of this work represents individuals that were protected by the OÖGKK in 2007. For this reason, those who were born during the period of observation (2008-2012) were eliminated as they were not part of the original standard population. However, people dying during this time were taken into account with an amount of person years equal to the time they lived through. Table 2 shows that in the case of this study the person years of most of the age strata are very close to five. The only exception is the sixth age strata (85+). However, this group does not hold a very high number of individuals, so it has only a limited effect. Nevertheless, the exact values were considered.

Moreover, similar to the study by Köster et al., a classification of diabetic subjects according to type 1 or type 2 was not possible due to the fact that there was no detailed diagnosis related information in the data of the statutory Upper Austrian health insurance company.

Finally, the cohort consisted of a total of 1,319,761 subjects. In the course of this work the five year stroke incidence for the period of 2008 to 2012 was analysed. This was mainly done on a sex-specific basis. Moreover, for the total, the diabetic and the non-diabetic population age/sex-specific as well as age/sex-standardized incidence rates of strokes were calculated. Therefore, the data was categorized into the following six age strata: 0-44, 45-54, 55-64, 65-74, 75-84, 85+.

As a further part of the analysis, relative risks (diabetic vs. non-diabetic population) were calculated from the (standardized Upper Austrian, Austrian and European) incidence rates. Attributable risks 
Table 2: Mean of observed person years in the observation period 2008-2012

\begin{tabular}{|l|l|l|}
\hline Age (years) & Diabetic & Non-diabetic \\
\hline $0-44$ & 4.994 & 4.956 \\
$45-54$ & 4.968 & 4.906 \\
$55-64$ & 4.919 & 4.804 \\
$65-74$ & 4.823 & 4.653 \\
$75-84$ & 4.453 & 4.181 \\
$85+$ & 3.716 & 3.400 \\
Overall & 4.935 & 4.628 \\
\hline
\end{tabular}

among exposed and population attributable risks due to diabetes were determined. In addition to these measures, a number of confidence intervals were calculated.

The analyses were conducted with the Statistical Analysis System (SAS 9.3) and will be described in more detail below.

\subsection{Incidence rates}

Assuming a Poisson distribution the amount of brain attacks occurring in a particular age-time exposure cell is assumed to take the values $k=0,1,2, \ldots$ with probabilities:

$$
\operatorname{Pr}(K=k)=\mathrm{e}^{-\lambda m} \frac{(\lambda m)^{k}}{k !}
$$

where $\lambda$ denotes the unknown rate and $m$ is the amount of person years.

An estimate of the age specific incidence rate $\lambda_{i}$ (for sex-specific analysis), that an individual might develop a stroke in age group $i(i=1, \ldots, 6)$ is:

$$
\lambda_{i} \approx \frac{k_{i}}{m_{i}}
$$

where $k_{i}$ denotes the number of observed strokes and $m_{i}$ are the number of person years in the $i^{\text {th }}$ age group for both sexes. (Breslow and Day, 1987, p. 53) Therefore, the calculation of $\hat{\lambda}_{i}$ requires an exact calculation of the person years of the observation, as described in section 3.1.

Let $\omega_{i}$ stand for the frequency of individuals in the $i^{\text {th }}$ age group of the standard population, hence $\omega_{i} \cdot \hat{\lambda}_{i}$ represents the number of expected cases that might be observed in the $i^{\text {th }}$ age group of the standard population if it were exposed to a level of risk defined by the rate $\hat{\lambda}_{i}$. The standardized incidence rate is then:

$$
\lambda_{s}=\sum_{i=1}^{6} \omega_{i} \cdot \hat{\lambda}_{i}
$$

with variance

$$
\widehat{\operatorname{Var}}\left(\lambda_{s}\right)=\sum_{i=1}^{6} \frac{\omega_{i}^{2}}{m_{i}^{2}} \cdot k_{i}
$$

(Breslow and Day 1987, p.59).

As Icks et al. (2011), a total of three age/sex-specific incidence rates were considered:

- All strokes in the total population $\left(\lambda_{\cdot i}\right)$

- Strokes in individuals with diabetes in the population with diabetes $\left(\lambda_{1 i}\right)$

- Strokes in individuals without diabetes in the population without diabetes $\left(\lambda_{0 i}\right)$ 
Additionally, incidence rates for the standardized Upper Austrian, Austrian (both of 2007) and European population (of 2010) $)^{2}$ were estimated.

\subsection{Effect measures}

For the calculation of the conventional effect measures two dichotomous variables were defined:

$$
S=\left\{\begin{array}{ll}
1 & \text { stroke } \\
0 & \text { nostroke }
\end{array} \quad D= \begin{cases}1 & \text { diabetic } \\
0 & \text { notdiabetic }\end{cases}\right.
$$

Let $\lambda_{1 i}=\operatorname{Pr}[S=1 \mid D=1]$ and $\lambda_{0 i}=\operatorname{Pr}[S=1 \mid D=0]$ be the stratum-specific incidence rates in the $i^{\text {th }}$ age-stratum which also denote whether or not diabetes has been diagnosed.

The relative risk (RR) of stroke, defined as the ratio of the stratum-specific incidences is:

$$
\mathrm{RR}_{i}=\frac{\lambda_{1 i}}{\lambda_{0 i}}=\frac{\operatorname{Pr}[S=1 \mid D=1]}{\operatorname{Pr}[S=1 \mid D=0]}
$$

(Breslow and Day 1980, p. 55).

The proportion

$$
\mathrm{ARE}_{i}=\frac{\lambda_{1 i}-\lambda_{0 i}}{\lambda_{1 i}}=\frac{\mathrm{RR}_{i}-1}{\mathrm{RR}_{i}}
$$

is labelled as the attributable risk for exposed individuals (ARE) (Cole and MacMahon 1971, p. 242). If $\delta_{i}$ denotes the proportion of diabetics in the strata population, then the total disease incidence is

$$
\lambda_{\cdot i}=\delta_{i} \cdot \lambda_{1 i}+\left(1-\delta_{i}\right) \cdot \lambda_{0 i}
$$

the population attributable risk (PAR) is calculated as follows:

$$
\mathrm{PAR}_{i}=\frac{\delta_{i} \cdot\left(\lambda_{1 i}-\lambda_{0 i}\right)}{\delta_{i} \cdot \lambda_{1 i}+\left(1-\delta_{i}\right) \cdot \lambda_{0 i}}=\frac{\delta_{i} \cdot\left(\mathrm{RR}_{i}-1\right)}{\delta_{i} \cdot \mathrm{RR}_{i}+\left(1-\delta_{i}\right)}
$$

(Cole and MacMahon 1971, p. 242; Breslow and Day 1980, p. 74).

\section{Results}

\subsection{Study population}

During the period of observation 1,319,761 subjects were secured by the OÖGKK, 649,907 (49.2 \%) men and 669,854 (50.8\%) women. These subjects, who account for 6,494,429 person years during 2008 and 2012 ( 4.9 years per person), did not have a stroke for at least one year before study entry. A total of 60,330 individuals were diagnosed as diabetic (30,516 men (50.6\%); 29,814 women (49.4 $\%)$ ). With an average age (Sd.) of 74.0 (10.7) versus 71.0 (15.0) years diabetics were older than non-diabetics (men: 71.1 (10.2) vs. 67.9 (14.6); women: 76.7 (10.3) vs. 73.5 (14.6)).

During the period of 2008 to 2012 17,663 subjects had a first stroke. Their mean age was 71.6 (14.3) years and 46.0 per cent of them were male. Among the stroke patients 19.5 percent were classified as diabetics accounting for 20.7 percent male and 18.5 percent female. Table 4 gives a more detailed overview of the number of first strokes.

According to the distribution of strokes, the following results emerged: transient cerebral ischaemic attacks and related syndromes (G45), 30.2\%; (subarachnoid, intracerebral, intracranial) haemorrhage (I60-I62), $13.8 \%$; cerebral infarction (I63), $45.8 \%$; strokes that were not specified as haemorrhage or infarction (I64), $10.2 \%$.

\footnotetext{
${ }^{2} 2013$ was a review of the European standard population of 1976. We use the quinquennial population 2010 from EU-28 which better reflect the characteristics of the EU-population.
} 
Table 3: Description of the study population

\begin{tabular}{|l|l|l|l|}
\hline & Total & Men & Women \\
\hline Study population, n (\%) & $1,319,761(100)$ & $649,907(49.2)$ & $669,854(50.8)$ \\
Diabetes, n (\%) & $60,330(100)$ & $30,516(50.6)$ & $29,814(49.4)$ \\
Mean age, years (Sd.) & $74.0(10.7)$ & $71.1(10.2)$ & $76.7(10.3)$ \\
Stroke, n (\%) & $17,663(100)$ & $8,132(46.0)$ & $9,531(54.0)$ \\
Mean age, years (Sd.) & $71.6(14.3)$ & $68.5(13.8)$ & $74.1(14.2)$ \\
\hline
\end{tabular}

Table 4: Description of the OÖGKK insurants with stroke, Upper Austria, 2008-2012

\begin{tabular}{|l|l|l|l|l|}
\hline & \multicolumn{2}{|c|}{ Men } & \multicolumn{2}{|c|}{ Women } \\
\hline & $\begin{array}{l}\text { diabetes } \\
(\mathrm{n}=1,680)\end{array}$ & $\begin{array}{l}\text { No diabetes } \\
(\mathrm{n}=6,452)\end{array}$ & $\begin{array}{l}\text { diabetes } \\
(\mathrm{n}=1,763)\end{array}$ & $\begin{array}{l}\text { No diabetes } \\
(\mathrm{n}=7,768)\end{array}$ \\
\hline Mean age, years (Sd.) & $71.1(10.2)$ & $67.9(14.6)$ & $76.7(10.3)$ & $73.5(14.9)$ \\
\hline Age groups, $\mathrm{n}(\%)$ & & & & \\
\hline $0-44$ & $29(1.7)$ & $609(9.4)$ & $21(1.2)$ & $525(6.8)$ \\
$45-54$ & $131(7.8)$ & $879(13.6)$ & $68(3.9)$ & $638(8.2)$ \\
$55-64$ & $421(25.1)$ & $1328(20.6)$ & $212(12.0)$ & $962(12.4)$ \\
$65-74$ & $635(37.8)$ & $1758(27.2)$ & $533(30.2)$ & $1889(24.3)$ \\
$75-84$ & $400(23.8)$ & $1510(23.4)$ & $702(39.8)$ & $2620(33.7)$ \\
$85+$ & $64(3.8)$ & $368(5.7)$ & $227(12.9)$ & $1134(14.6)$ \\
\hline Age refers to age at time of first stroke. \\
\hline
\end{tabular}

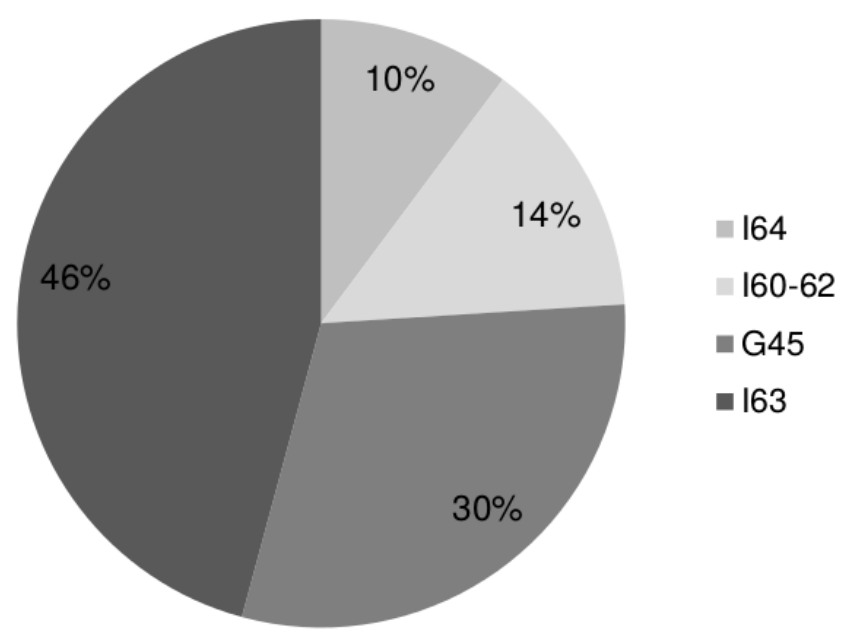

Figure 1: Distribution of strokes 


\subsection{Incidence of stroke}

Table 5 presents details about the age/sex-specific incidence rates. Stroke incidence increased with age in both sexes. Consequently, the highest stroke incidence occurred for subjects being older than 85 years with 2437.6 strokes per 100,000 of the total study population (men: 2610.1; women: 2387.5), 3267.6 per 100,000 in diabetic subjects (men: 3318.6; women: 3253.4 ) and 2323.2 per 100,000 in non-diabetic subjects (men: 2516.7; women: 2266.7). The most drastic absolute increase of stroke incidence could be observed from the forth (65-74) to the fifth (75-84) age stratum (see also Figure 4 and 5). Regarding the female population, the total incidence rate for 75-84 year olds was more than two times as high as for the 65-74 year olds. A similar effect could be seen for the male population.

0-44 year old subjects suffering from diabetes showed a stroke incidence that was more than five times as high as for their non-diabetic complements. Diabetics of the age classes 45-54 and 55-64 showed an at least two-fold incidence rate compared to non-diabetics. The same effect could be observed by looking at men and women separately. The difference of stroke incidence between diabetics and non-diabetics declined a little for the latter three age strata, but the diabetic subjects still suffered from a stroke more often. (Details see 4.3)

Figure 2 visualizes the standardized incidence rates. Moreover, it stresses the difference between the incidences of stroke among diabetics relative to the one among non-diabetics.

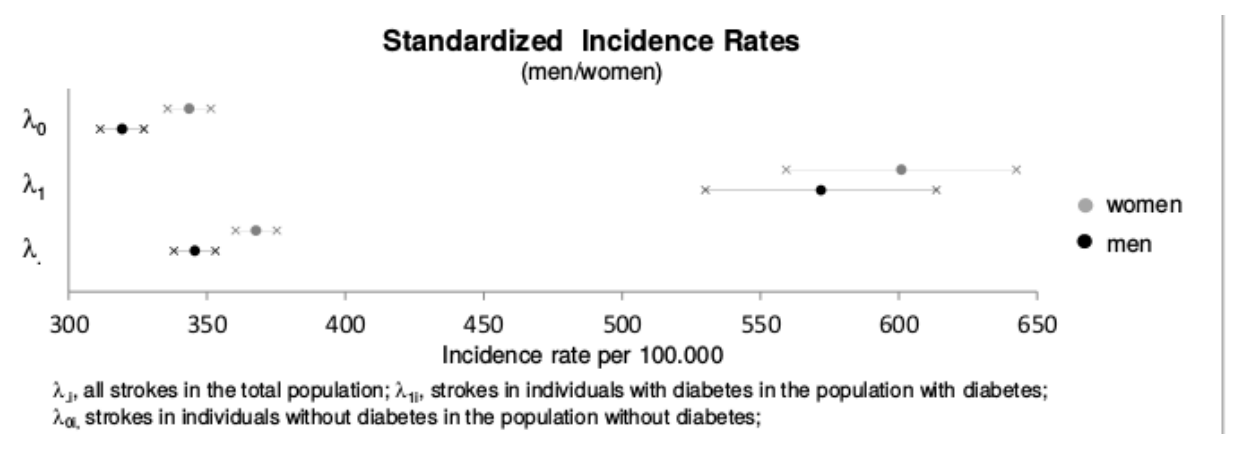

Figure 2: Standardized incidence rates for men and women, Upper Austria

Figure 2 illustrates that there is a significant difference between the stroke risk of women and men not suffering from diabetes. Yet no significant difference between the stroke risk of women and the stroke risk of men that are suffering from diabetes can be observed. This indicates that there must be a sex-specific effect that influences the natural stroke risk which disappears for diabetics (see 5.1).

For the standardized incidence rate of strokes (per 100,000 person years) of the Upper Austrian population, the result of the observation period (2008-2012) was 354.7 (95\% CI $=349.5-360.0)$ for the total population, $591.4(95 \% \mathrm{CI}=561.8-620.9)$ in diabetic subjects and $329.0(95 \% \mathrm{CI}=323.5$ $334.5)$ in non-diabetic subjects.

The standardized values of the Austrian and European population are quite similar.

\subsection{Effect measures}

The results of the effect measures that are given in Table 6 show that diabetes can be associated with the incidence of stroke.

The overall relative risk, the overall attributable risk for exposed and the overall population attributable risk are not represented as they are difficult to interpret. The main reason for this is that the first age group (0-44) is bigger than the other age groups. Hence, it has a strong impact on the overall result of the effect measures. However, this age stratum specific effect is taken into account in the overall relative and attributable risks that are standardized to the Upper Austrian, Austrian and European population.

For those that are 44 years old or younger (first age group: 0-44) diabetes has the worst influence on the incidence of stroke. The risk of getting a stroke is 5.44 (men: 5.55, women: 5.26) times higher for 
Table 5: Standardized incidence rates for men and women, Upper Austria

\begin{tabular}{|c|c|c|c|c|c|c|}
\hline & \multicolumn{2}{|l|}{$\lambda_{\cdot i}$} & \multicolumn{2}{|l|}{$\lambda_{1 i}$} & \multicolumn{2}{|l|}{$\lambda_{0 i}$} \\
\hline Men & & & & & & \\
\hline Age (years) & & & & & & \\
\hline $\begin{array}{l}0-44 \\
45-54 \\
55-64 \\
65-74 \\
75-84 \\
85+\end{array}$ & $\begin{array}{l}29.1 \\
231.1 \\
629.9 \\
1250.0 \\
2118.8 \\
2610.1\end{array}$ & $\begin{array}{l}(26.9-31.5) \\
(217.1-245.9) \\
(600.7-660.1) \\
(1200.4-1301.1) \\
(2024.9-2216.0) \\
(2369.8-2868.2)\end{array}$ & $\begin{array}{l}156.0 \\
434.9 \\
1030.7 \\
1798.0 \\
2633.2 \\
3318.6\end{array}$ & $\begin{array}{l}(104.5-224.0) \\
(363.7-516.1) \\
(934.6-1134.0) \\
(1660.8-1943.4) \\
(2381.4-2904.3) \\
(2555.8-4237.8)\end{array}$ & $\begin{array}{l}28.1 \\
216.1 \\
560.8 \\
1126.0 \\
2014.6 \\
2516.7\end{array}$ & $\begin{array}{l}(25.9-30.4) \\
(202.0-230.8) \\
(531.0-591.8) \\
(1074.0- \\
1179.9) \\
(1914.2- \\
2118.8) \\
(2266.1- \\
2787.4)\end{array}$ \\
\hline All & 254.0 & $(248.5-259.6)$ & 1183.2 & $(1127.2-1241.1)$ & 210.9 & $(205.8-216.1)$ \\
\hline $\begin{array}{l}\text { Standard: Upper } \\
\text { Austrian } \\
\text { population }\end{array}$ & 345.6 & $(338.0-353.3)$ & 571.9 & $(530.1-613.6)$ & 319.3 & $(311.3-327.2)$ \\
\hline $\begin{array}{l}\text { Standard: } \\
\text { Austrian } \\
\text { Population }\end{array}$ & 353.3 & $(345.5-361.1)$ & 582.1 & $(540.3-623.9)$ & 326.3 & $(318.1-334.4)$ \\
\hline $\begin{array}{l}\text { Standard: } \\
\text { European } \\
\text { Population }\end{array}$ & 376.7 & $(368.2-385.1)$ & 611.7 & $(569.4-653.9)$ & 348.2 & $(339.4-357.0)$ \\
\hline Women & & & & & & \\
\hline Age (years) & & & & & & \\
\hline $\begin{array}{l}0-44 \\
45-54 \\
55-64 \\
65-74 \\
75-84 \\
85+ \\
\text { All }\end{array}$ & $\begin{array}{l}26.5 \\
161.8 \\
383.1 \\
926.8 \\
1926.5 \\
\\
2387.5 \\
\\
289.5\end{array}$ & $\begin{array}{l}(24.3-28.8) \\
(150.0-174.1) \\
(361.5-405.6) \\
(890.2-964.4) \\
(1861.5-1993.1) \\
(2262.3-2517.8) \\
(283.7-295.3)\end{array}$ & $\begin{array}{l}135.2 \\
376.1 \\
707.6 \\
1378.0 \\
2508.8 \\
\\
3253.4 \\
1284.9\end{array}$ & $\begin{array}{l}(83.7-206.6) \\
(292.1-476.8) \\
(615.5-809.5) \\
(1263.5-1500.1) \\
(2326.6-2701.4) \\
(2843.9-3705.3) \\
(1225.6-1346.3)\end{array}$ & $\begin{array}{l}25.7 \\
152.5 \\
347.9 \\
848.4 \\
1813.7 \\
\\
2266.7 \\
\\
246.2\end{array}$ & $\begin{array}{l}(23.5-28.0) \\
(140.9-164.8) \\
(326.3-370.6) \\
(810.5-887.5) \\
(1744.9- \\
1884.5) \\
(2136.7- \\
2402.6) \\
(240.7-251.7)\end{array}$ \\
\hline $\begin{array}{l}\text { Standard: Upper } \\
\text { Austrian } \\
\text { population }\end{array}$ & 367.7 & $(360.3-375.2)$ & 600.9 & $(559.3-642.5)$ & 343.5 & $(335.7-351.3)$ \\
\hline $\begin{array}{l}\text { Standard: } \\
\text { Austrian } \\
\text { Population }\end{array}$ & 375.6 & $(368.0-383.3)$ & 611.6 & $(569.9-653.2)$ & 350.9 & $(342.9-358.8)$ \\
\hline $\begin{array}{l}\text { Standard: } \\
\text { European } \\
\text { Population }\end{array}$ & 383.9 & (376.1-391.7) & 624.0 & $(582.5-665.5)$ & 358.4 & $(350.3-366.5)$ \\
\hline
\end{tabular}


Table 6: Relative risk with confidence intervals (men/women)

\begin{tabular}{|c|c|c|c|c|c|c|}
\hline & \multicolumn{2}{|l|}{$\mathrm{RR}_{i}$} & \multicolumn{2}{|c|}{$\mathrm{ARE}_{i}$} & \multicolumn{2}{|c|}{$\mathrm{PAR}_{i}$} \\
\hline Men & & & & & & \\
\hline Age (years) & & & & & & \\
\hline $\begin{array}{l}0-44 \\
45-54 \\
55-64 \\
65-74 \\
75-84 \\
85+\end{array}$ & $\begin{array}{l}5.55 \\
2.01 \\
1.84 \\
1.60 \\
1.31 \\
1.32\end{array}$ & $\begin{array}{l}(3.83-8.07) \\
(1.68-2.42) \\
(1.65-2.05) \\
(1.46-1.75) \\
(1.17-1.46) \\
(1.01-1.72)\end{array}$ & $\begin{array}{l}0.82 \\
0.50 \\
0.46 \\
0.37 \\
0.23 \\
0.24\end{array}$ & $\begin{array}{l}(0.74-0.88) \\
(0.40-0.59) \\
(0.39-0.51) \\
(0.31-0.43) \\
(0.15-0.31) \\
(0.01-0.42)\end{array}$ & $\begin{array}{l}0.04 \\
0.07 \\
0.11 \\
0.10 \\
0.05 \\
0.04\end{array}$ & $\begin{array}{l}(0.02-0.06) \\
(0.04-0.09) \\
(0.09-0.13) \\
(0.08-0.12) \\
(0.03-0.07) \\
(0.00-0.08)\end{array}$ \\
\hline $\begin{array}{l}\text { Standard: Upper } \\
\text { Austrian } \\
\text { population }\end{array}$ & 1.79 & (1.66-1.93) & 0.44 & $(0.40-0.48)$ & 0.08 & $(0.04-0.11)$ \\
\hline $\begin{array}{l}\text { Standard: Austrian } \\
\text { population }\end{array}$ & 1.78 & $(1.65-1.93)$ & 0.44 & $(0.40-0.48)$ & 0.08 & $(0.05-0.11)$ \\
\hline $\begin{array}{l}\text { Standard: European } \\
\text { population }\end{array}$ & 1.76 & $(1.63-1.89)$ & 0.43 & $(0.39-0.47)$ & 0.08 & $(0.04-0.11)$ \\
\hline Women & & & & & & \\
\hline Age (years) & & & & & & \\
\hline $\begin{array}{l}0-44 \\
45-54 \\
55-64 \\
65-74 \\
75-84 \\
85+\end{array}$ & $\begin{array}{l}5.26 \\
2.47 \\
2.03 \\
1.62 \\
1.38 \\
1.44\end{array}$ & $\begin{array}{l}(3.40-8.14) \\
(1.92-3.17) \\
(1.75-2.36) \\
(1.48-1.79) \\
(1.27-1.50) \\
(1.24-1.66)\end{array}$ & $\begin{array}{l}0.81 \\
0.59 \\
0.51 \\
0.38 \\
0.28 \\
0.30\end{array}$ & $\begin{array}{l}(0.71-0.88) \\
(0.48-0.68) \\
(0.43-0.58) \\
(0.32-0.44) \\
(0.21-0.33) \\
(0.20-0.40)\end{array}$ & $\begin{array}{l}0.03 \\
0.06 \\
0.09 \\
0.08 \\
0.06 \\
0.05\end{array}$ & $\begin{array}{l}(0.02-0.05) \\
(0.04-0.08) \\
(0.07-0.12) \\
(0.07-0.10) \\
(0.04-0.08) \\
(0.03-0.07)\end{array}$ \\
\hline $\begin{array}{l}\text { Standard: Upper } \\
\text { Austrian } \\
\text { population }\end{array}$ & 1.75 & $(1.63-1.88)$ & 0.43 & $(0.39-0.47)$ & 0.07 & $(0.04-0.09)$ \\
\hline $\begin{array}{l}\text { Standard: Austrian } \\
\text { population }\end{array}$ & 1.74 & $(1.62-1.87)$ & 0.43 & $(0.38-0.47)$ & 0.07 & $(0.04-0.09)$ \\
\hline $\begin{array}{l}\text { Standard: European } \\
\text { population }\end{array}$ & 1.74 & $(1.62-1.87)$ & 0.43 & $(0.39-0.47)$ & 0.07 & $(0.04-0.09)$ \\
\hline
\end{tabular}


a diabetic person of this age group compared to a non-diabetic. The risk of a diabetic person of the second age group (45-54 years) is already considerably smaller, but still more than twice as high as the risk of a person not suffering from diabetes. The relative risk of getting a stroke declines for each age stratum but always stays significantly larger than 1. (see Figure 3).

Standardized individual attributable risk $\left(\mathrm{ARE}_{s}\right)$ values show that, 44 per cent of all strokes in the standardized male diabetic population are due to diabetes (women: $43 \%$ ). Looking at these results on an age/sex-specific basis, it can be seen that about 80 per cent of the strokes among diabetics in the first age stratum (0-44 years) are due to diabetes. For diabetic women of the second (45-54 years) and third (55-64 years) age class, more than half of the strokes could be avoided if diabetes did not exist any longer. Concerning the latter age groups, the impact of diabetes decreases a little but stays of considerable size. The same effect can be observed for male subjects.

Furthermore, the population attributable risk (PAR) tells us that 8 per cent of all strokes of the total Upper Austrian population are due to diabetes. The third (55-64 years) and fourth (65-74 years) age groups are exposed to the highest additional risk (men: $11 \%, 10 \%$ respectively; women: $9 \%, 8 \%$ respectively).

After the standardized incidence rates of Austria and Europe for diabetic and non-diabetic subjects are quite similar to those of Upper Austria (with equal proportion), we obtain same results for the standardized effect measures.

\section{Discussion}

\subsection{Study findings}

This study quantified incidence rates of brain attacks in order to compare the diabetic and non-diabetic population in Upper Austria between 2008 and 2012. Moreover, relative and attributable stroke risks due to diabetes were estimated. The results illustrated that there is a strong association between diabetes and stroke. By looking at the confounders age and sex, there are significant differences due to sex. Furthermore, the first age-group (0-44 years) differs significantly from the others. As the results of each stratum are higher for diabetics than for non-diabetics the intentions of the Austrian disease management program for patients suffering from diabetes or the diabetics-prevention campaign of the Austrian Diabetic Society (ÖDG) are important in order to decrease the number of diabetics and thus the occurrence of strokes.

Table 5 indicates that in each age strata the stroke risk was higher in men compared to women. However, looking at the sex-specific incidence rate of all age strata, it must be pointed out that more strokes occurred among female subjects. Uncritical use of these conflicting rates may lead to misinterpretations. $^{3}$

By standardizing the incidence rate of strokes (per 100,000 person years) to the Upper Austrian, Austrian and European population the same effect can be observed. This is due to the fact that the amount of female subjects in the age group $85+$ is a lot more elevated than the one of men. As the risk in this age group is very high, it has a strong impact on the overall incidence rate.

\subsection{Comparison to other studies}

As expected, the stroke incidence found in the course of this study is a bit higher compared to other studies (Truelsen et al. 2006; Icks et al. 2011). Truelsen et al. estimated stroke incidence rates in Europe with the help of available data on stroke from various studies. Among other countries, the age/sex-specific stroke incidence rates were also estimated for Austria. Although the estimated incidence rates are lower than the results obtained in this study, it can be seen that the overall trend is similar. In both cases, the incidence rate rises exponentially and men have a higher stroke risk than women. However, it must be kept in mind that the estimates of Truelsen et al. (2006) refer to the

\footnotetext{
${ }^{3}$ For this reason the overall risks have not been presented.
} 
whole country, while the results of this study only relate to Upper Austria. The same effect can be observed on the results of Icks et al. (2011) who looked at the German population. The differences and similarities of the incidence of stroke of the three studies are visualized in Figure 4 and 5.

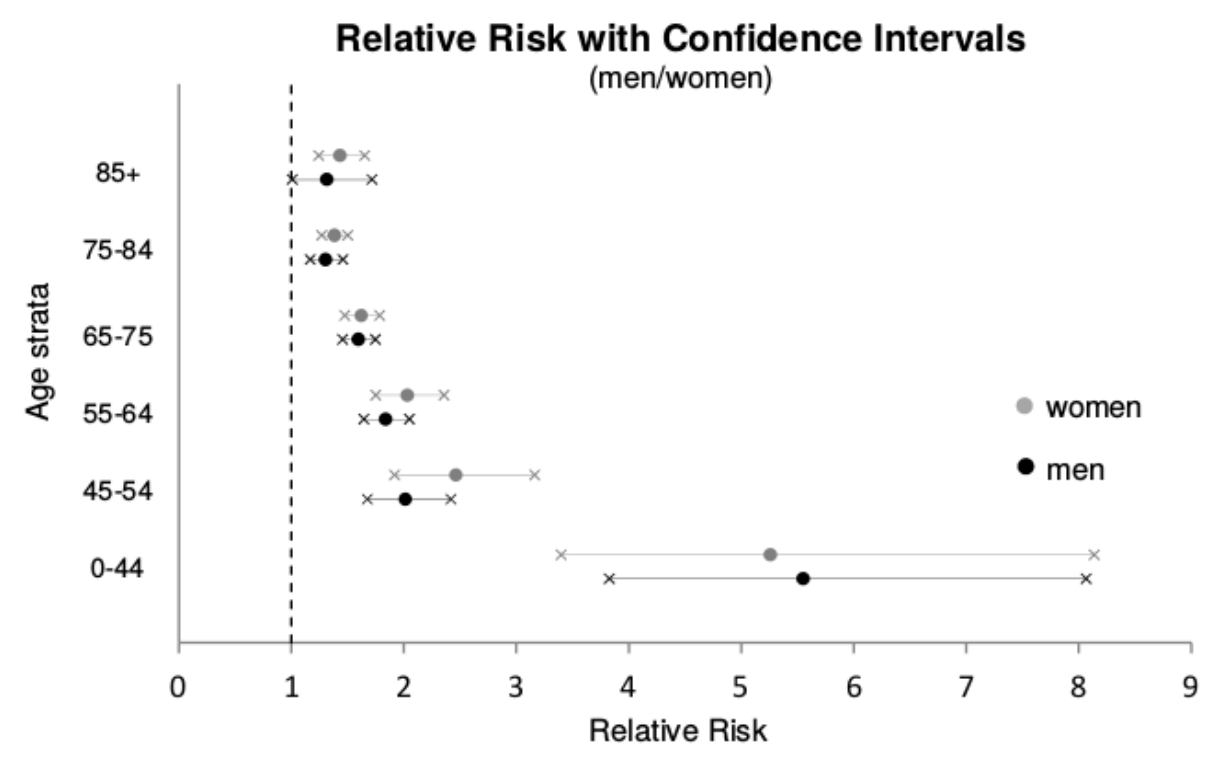

Figure 3: Incidence of stroke for men

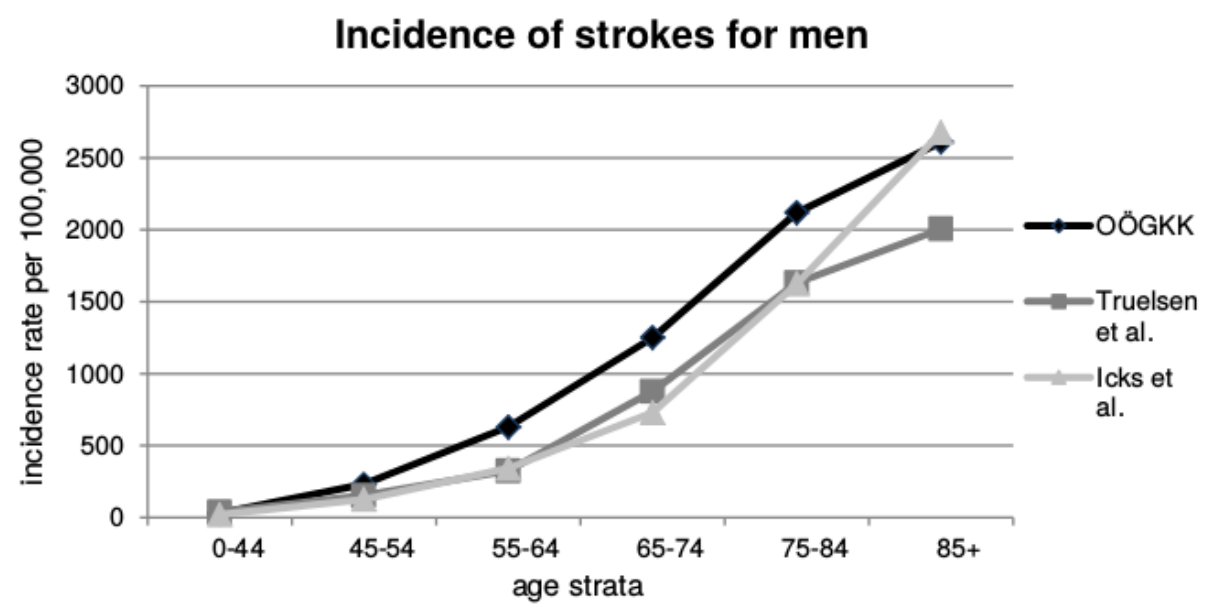

Figure 4: Incidence of stroke for women

Only a limited proportion of population-based studies concentrated on stroke rates in the diabetic and the non-diabetic population (Jeerakathil et al. 2007, Icks et al. 2011). Once again, the same overall trend can be observed when comparing the results of Icks et al. (2011) to this study. Nevertheless, Icks et al.'s results are a bit lower.

Regarding effect measures, various international studies (Icks et al. 2011; Chen et al. 2009; Lin et al. 2007; Kissela et al. 2005) obtained results that are in line with this investigation. Multiple works emphasized a strong association between diabetes and the outcome of stroke especially in lower age groups. Furthermore, it was frequently pointed out that there is no significant difference between the two sexes. Various studies referred to the fact that the relative stroke risk for diabetic women being older than 85 is considerably higher than the relative risk for diabetic men of the same age class which is probably due to the fact that women get older than men.

\subsection{Limitations and strengths}

Concerning this study, a number of limitations have to be taken into account. First of all, it has to 
be said that due to the fact that health insurance data was used, it may have come to some misclassification because of coding mistakes. It is for instance possible that the incidence of stroke was overestimated as vertigo might have been diagnosed as very slight stroke and therefore recorded as cerebral ischaemic attack and related syndromes (G45). Especially during the first part of the observation period the occurrence of this coding mistake is very likely. But due to the existence of the UASR the record of strokes improved over time. For this reason, it would be interesting to replicate the study by only taking the second half of the five-year period into consideration or by ignoring G45 diagnoses. Moreover, the stroke incidence might have been underestimated because fatal strokes and strokes that were treated outside hospitals could not be considered as no data was available in these cases. However, according to Kolominsky-Rabas et al. (1998) about $95 \%$ of strokes are hospitalized. Therefore, it can be assumed that the number of strokes not being hospitalized can be neglected. In addition, it has to be said that confounding variables were not analysed in this study. But Icks et al. (2011) showed that confounding variables like for instance hypertension, dyslipidemia and atrial fibrillation did not influence the stroke rate. A further limitation is that there might be some misclassification in the identification of diabetics, although Köster et al.'s (2007) algorithm to determine diabetics, which was already used by other studies (Icks et al. 2011), was considered. Another point of criticism is that the subjects included in this investigation might not be fully representative for the Upper Austrian population as farmers, teacher, officials and employers are not protected by the OÖGKK. Nevertheless, it can be assumed that this has no considerable impact on the results, as these population groups only represent a small proportion of the Upper Austrian population. This may probably not be neglected for Austrian and European population.

A strength of this study is that the investigations used original data. The database that was used was very large and therefore represents a considerable part (86 \%) of the Upper Austrian population. So even if this study only covers a well-defined region it covers this region almost completely. Therefore, it can be used as comparison for studies that deal with large areas but only pick a limited number of cases from each region. Moreover, the time interval of five years that was investigated was large. In addition, by taking every lived through month into account the calculation of person years was very exact. Another strength is that the person years of subjects who were diagnosed as diabetics during the observation period of 2008 to 2012 were adjusted.

Acknowledgements This study was part of a summer research project and supported by the Upper Austrian Stroke Register and the statutory Upper Austrian health insurance. We would like to thank the 14 Upper Austrian hospitals and the number of other institutions that are reporting data to the UASR. For details see:

http://www.ooegkk.at/portal27/portal/ooegkkportal/channel_content/cmsWindow?p_tabid=5\& p_menuid $=62297 \&$ action $=2$

We thank Dr. Andreas Baierl for useful comments and the editor and referees for their valuable and constructive suggestions which helped us to improve the aim of this article.

\section{References}

Almdal, T; Scharling, H.;Jensen, J. S.;Vestergaard, H. (2004). The Independent Effect of Type 2 Diabetes Mellitus on Ischemic Heart Disease, Stroke and Death: A Population-based Study of 13,000 Men and Women with 20 Years of Follow-up. Archives of Internal Medicin, 164(13), 1422-1426.

Breslow, N. E.; Day, N. E. (1980). Statistical Methods in Cancer Research - Volume 1 - The Analysis of Case-control Studies. Lyon, International Agency for Research on Cancer.

Breslow, N. E.; Day, N. E. (1987). Statistical Methods in Cancer Research - Volume 2 - The Design and Analysis of Cohort Studies. Lyon, International Agency for Research on Cancer.

Bundesministerium für Gesundheit (Hrsg), (2012). Internationale Statistische Klassifikation der Krankheiten und Verwandter Gesundheitsprobleme 10. Revision - BMG-Version 2013, Wien. (http://bmg.gv.at/cms/home/attachments/1/1/2/CH1241/CMS1287572751172/icd-10_bmg_2013__systematisches_verzeichnis.pdf) [accessed on 26/07/13] 
Chen, H. F.; Lee, S. P.; Li, C. Y. (2009). Sex Differences in the Incidence of Hemorrhagic and Ischemic Stroke among Diabetics in Taiwan. Journal Womens Health, 18 (5), 647-654.

Cole, P.; MacMahon, B., (1971). Attributable Risk Percent in Case-control Studies. British Journal of Preventive \& Social Medicine, 25, 242-244

Diabetes Care and Research in Europe, (1989). The Saint Vincent Declaration. World Health Organization, ICP/CLR 034.

Esteve, J.; Benhamou, E.; Raymond, L. (1994). Descriptive Epidemiology. 4 ed.. Lyon, International Agency for Research on Cancer.

Fisz, M. (1989). Wahrscheinlichkeitsrechnung und Mathematische Statistik. Berlin, VEB Deutscher Verlag der Wissenschaften.

Grysiewiez, R.; Thomas, K.; Pandey, D. K. (2008). Epidemiology of Ischemic and Hemorrhagic Stroke: Incidence, Prevalence, Mortality and Risk Factors. Neurologic clinics, 26 (4), 871-895.

Icks, A.; Scheer, M.; Genz, J.; Giani, G.; Glaeske, G.; Hoffmann, F. (2011), Stroke in the Diabetic and Non-diabetic Population in Germany: Relative and Attributable Risks, 2005-2007. Journal of Diabetes and its Complications, 25, 90-96.

Jeerakathil, T.; Johnson, J. A.; Simpson, S. H.; Majumdar, S. R. (2007). Short-term Risk for Stroke is Doubled in Persons with Newly Treated Type 2 Diabetes Compared with Persons without Diabetes: A Population-based Cohort Study. Stroke, 38 (6), 1739-1743.

Kahn, H. A.; Sempson, C. T. (1989). Statistical Methods in Epidemiology. New York, Oxford University Press.

Kissela, B. M.; Khoury, J.; Kleindorfer, D.; Woo, D.; Schneider, A.; Alwell, K.; Miller, R.; Ewing, I.; Moomaw, C. J.; Szaflarski, J. P.; Gebel, J.; Shukla, R.; Broderick, J. P. (2005). Epidemiology of Ischemic Stroke in Patients with Diabetes - The Greater Cincinnati/Northern Kentucky Stroke Study. Diabetes Care, 28 (2), 355-359.

Kolominsky-Rabas, P. L.;Sarti, C.; Heuschmann, P. U.; Graf, C.; Siemonsen, S.; Neundoerfer, B.; Katalinic, A.; Lang, E.; Gassmann, K. G.; von Stockert, T. (1998). A Prospective Community-based Study of Stroke in Germany: The Erlangen Stroke Project (SEPro). Incidence and Case Fatality at 1, 3 and 12 Months. Stroke, 29 (12), 2501-2506.

Köster, I.; von Ferber, L.; Ihle, P.; Schubert, I.; Hauner, H. (2006). The Cost Burden of Diabetes Mellitus: the Evidence from Germany-the CoDiM Study. Köln, Springer-Verlag.

Lackland, D.; Roccella, E.; Deutsch, A. et al. (2014). Factors Influencing the Decline in Stroke Mortality: A Statement from the American Heart Association/American Stroke Association. Stroke, 45:315-353, 326-327

Lin, M.; Chen, Y.; Sigal, R. J. (2007). Stroke Associated with Diabetes among Canadians: Sex and Age Differences. Neuroepidemiology, 28 (1), 46-49.

National Stroke Association (2013). What is a stroke?

http://www.stroke.org/site/PageServer?pagename=stroke [accessed on 26/07/13].

Österreichische Diabetes Gesellschaft (ÖGD) (2013): Campaign 2013.

http://www.oedg.org/kampagnen.html [accessed on 15/12/2014]

Österreichische Schlaganfallgesellschaft (ÖGSF) (2010). Schlaganfallprävention bei Patienten mit Diabetes mellitus Typ 2 - Positionspapier Dezember 2010.

http://www.oegsf.at/aerzte/uploads/Positionspapiere/Positionspapier_Schlaganfallpraevention\%20bei \%20Patienten\%20mit\%20DM\%20II_Version\%20Dez\%202010.pdf [accessed on 27/08/2013]

Ross, J. (2012). Nervous System, 4 ed.. Elsevier Health Sciences.

Truelsen, T.; Piechowski-Jóźwiak, B.; Bonita, R.; Mathers, C.; Bogousslavsky, J.; Boysen, G. (2006). Stroke Incidence and Prevalence in Europe: a Review of Available Data. European Journal of Neurology, 13 (6), 581-598.

United Nations, Department od Economics and Social Affairs, 2012. World Population

Prospects. (http://esa.un.org/unpd/wpp/Excel-Data/population.htm) 


\section{Affiliation:}

Karl Schableger

Oberösterreichische Gebietskrankenkasse

Gruberstrasse 77,

4020 Linz,

Austria

E-mail: karl.schableger@ooegkk. at

Lisa Inreiter

Oberösterreichische Gebietskrankenkasse

Gruberstrasse 77,

4020 Linz,

Austria

Austrian Journal of Statistics

published by the Austrian Society of Statistics

Volume 44

October 2015 http://www.ajs.or.at/

http://www.osg.or.at/

Submitted: 2014-05-16

Accepted: 2015-01-12 